\title{
NUMERICAL SIMULATION OF TEMPERATURE DISTRIBUTION ON METAL CASTING IN VERTICAL SOLIDIFICATION
}

\author{
G. M.Stieven ${ }^{a}$, \\ D. R. Soares ${ }^{a}$, \\ E. P. Oli veirab, \\ and E. F. Lins ${ }^{\text {a }}$ \\ ${ }^{a}$ Universidade Federal do Pará \\ Departamento de Engenharia Mecânica \\ Rua Augusto Corrêa \\ CEP. 66075-1 10, Belém, Pará, Brasil \\ gianfrancostieven@yahoo.com.br \\ dani_ddrs@yahoo.com.br \\ erb@ufpa.br \\ ${ }^{\mathrm{b}}$ Universidade Federal do Sul e Sudeste do Pará \\ Departamento de Engenharia Mecânica \\ CEP. 68505-080, Marabá,Pará, Brasil \\ edilma@unifesspa.edu.br \\ Received: April 16, 2018 \\ Revised: August 01, 2018 \\ Accepted: October 18, 2018 \\ ABSTRACT \\ simulation

\section{NOMENCLATURE} \\ A, B dimensionless heat transfer parameters \\ $h_{i} \quad$ interfacial heat transfer coefficient, $\mathrm{W} /\left(\mathrm{m}^{2} . \mathrm{K}\right)$ \\ $c_{p} \quad$ specific heat at constant pressure, $\mathrm{J} /(\mathrm{kg} . \mathrm{K})$ \\ $\vec{g} \quad$ gravitational constant, $\mathrm{m} / \mathrm{s}^{2}$ \\ $h \quad$ sensible heat, $\mathrm{J}$ \\ $H$ enthalpy, $\mathrm{J}$ \\ I unitary tensor \\ $K_{i} \quad$ dimensionless partition coefficient of solute \\ $k$ thermal conductivity, $\mathrm{W} /(\mathrm{m} . \mathrm{K})$ \\ $L \quad$ latent heat, $\mathrm{J} / \mathrm{kg}$ \\ $m \quad$ slope of the liquidus line, dimensionless \\ $N_{s} \quad$ number of species \\ $p \quad$ static pressure, \\ $\vec{v} \quad$ flu id velocity, $\mathrm{m} / \mathrm{s}$ \\ $T$ temperature, $\mathrm{K}$ \\ $T_{c} \quad$ temperature of the finite volume in contact \\ with the heat exchange interface, $\mathrm{K}$ \\ $T^{*} \quad$ temperature of the finite volu me interface, $\mathrm{K}$ \\ $t \quad$ time, $\mathrm{s}$ \\ $Y_{i} \quad$ mass fraction of the solute \\ $V \quad$ Volume \\ $D \quad$ mass diffusion coefficient, $\mathrm{m}^{2} / \mathrm{s}$
}

The metals and alloys solidification can be defined as a transient heat transfer process. A liquid/solid transformation is followed by thermal energy liberation, with a movable boundary separating two phases with different thermophysical properties. The solidification is of great interest to mechanical and chemical engineers. It is a non-linear transient phenomenon, where heat transfer between the casting and the mold plays a important role. This paper aims to propose a study of heat flow from the casting to the mold using a numerical technique to compute the temperature history of all points inside the casting. The cooling process consists of water-cooled mold with heat being extracted only from the bottom, resulting in unidirectional vertical solidification. The ANSYS software was used to obtain the temperature distribution in the casting. Good agreement was obtained when the simulation results were compared with the experimental data.

Keywords: upward solidification; transient heat transfer; numerical

\section{Greek symbols}

$\alpha \quad$ thermal diffusivity, $\mathrm{m}^{2} / \mathrm{s}$

$\beta \quad$ liquid fraction, dimensionless

$\Delta \quad$ variation

$\rho$ density, $\mathrm{kg} / \mathrm{m}^{3}$

$\mu \quad$ dynamic viscosity, Pa.s

$\lambda$ relaxation factor, dimensionless

$\alpha_{p} \quad$ cell matrix coefficient, dimensionless

$\tau$ shear tensor

$\nabla \quad$ vector operator gradient

\section{Subscripts}

i solute

$s \quad$ solid phase

$l \quad$ liquid phase

liquidus at liquidus line

solidus at solidus line

$\mathrm{mz} \quad$ at mushy zone

ref at reference

n number of iteration

\section{INTRODUCTION}

The solidification of metal alloys in molds plays 
an important role in many problems in materials engineering. During this process, a solidification front that progresses in the directions where the liquid metal still exists is formed and propagates at a speed that depends on the rate of heat extraction from the mold. The study of this process provides information of great importance for the determination of solidified metal mechanical properties such as strength, hardness, heat conductivity etc.

The metals solidification involved in foundries process can be fundamentally defined as a transient heat transfer process including phase modifications in which some heat energy may be transferred by mold from liquid phase to the ambient, enabling nucleation and solid phase growth. Casting rejections are of a major concern in the foundry industry. Great saving of materials, energy and time could be achieved, if casting design can be corrected prior to molding based on defects prediction.

In addition, there is a strong relationship between the cooling process and the mechanical performance of a component (Hachani et al., 2012; Şahin et al., 2006). The study on the thermal parameters that represent the thermal exchange of ingots is relevant since there are empirical equations that relate such factors (Castanho et al., 2015; Vida et al., 2016) with the mechanical properties of alloys of a certain system metallic. These works, besides being industrially important, can be input data for numerical simulation works to optimize manufacturing processes (WU et al., 2016; Wu; Ludwig; Karicha, 2017).

These facts make solidification simulation a useful tool to help predicting casting defects. Generally, the theoretical analysis of the solidification problem may be performed using exact analytical methods, approximate and, as shown in the current work, numerical methods. The solidification process presents several complications in their mathe matical model, being very common the study of such processes using experiments on a small scale and simplified setups, for example, where heat extraction in only one direction.

One of the most used approaches to the mathematical treatment of solidification regards energy conservation and the identification of the liquid-solid transition regions through a pseudoporosity methodology (Voller and Prakash 1987). The formulation so-called enthalpy-porosity is the one currently implemented in software ANSYS FLUENT (ANSYS, 2013). In this methodology, the equations for the liquid phase velocity are also considered. Unlike the solidification of pure substances, where it is observed a clearly defined solid-liquid interface, in alloys there is a mushy zone. Numerical treatment of this region has significant impact in predicting microstructures to be formed. The mushy zone is treated as a porous zone with porosity equal to the liquid fraction and appropriate terms are added to momentum and energy conservation equations to consider the formation of solid material. Sources terms are also added to the turbulence equations to be damp or cancel this influence according to the degree of solidity of the region.

The aim of this paper is to correlate the literature experimental thermal data to the ones provided from the software to investigate the physical and mathematical validation of this numerical formulation. In the present study, the binary Al$3 \mathrm{wt} . \% \mathrm{Si}$ is studied.

\section{GOVERNING EQUATIONS}

$$
\begin{gathered}
\frac{\partial}{\partial t}(\rho H)+\nabla \cdot(\rho \vec{v} H)=\nabla \cdot(k \nabla T) \\
H=h+\Delta H \\
h=h_{r e f}+\int_{T_{r e f}}^{T} c_{p} d T \\
\Delta H=\beta L \\
\mathrm{~h}_{\mathrm{i}}=\mathrm{At}^{\mathrm{B}}
\end{gathered}
$$

The unidirectional vertical upward solidification device consists of a metal mold cooled downwardly by convection, usually by water flow. This apparatus was developed to analyze the solidification phenomenon in a more stable way in terms of convection and grain growth, since the growth of the solid is contrary to the gravity vector, disfavoring the thermosolutal convection ahead of the solidification interface (Peres et al., 2004). When modeling this device, the Finite Difference Method (FDM) is often used as a method to solve the governing equations of the phenomena.

The solidification is predominantly recognized as a process of phase transformation, in which there is release or energy consumption by the material involved in the phenomenon. Thus, the energy equation, Eq. (1), must be present in its modeling. In this equation $\rho$ is the specific mass of the species, $\vec{v}$ is the fluid velocity, $k$ the thermal conductivity of the chemical species, $T$ is temperature, $\nabla$ is the vector operator gradient, which is defined as the derivative of a spatial vector field, and $t$ is the time.

The enthalpy involved in the phase transformation process, expressed by $\Delta H$, is closely linked to the latent and sensible energy, as shown in Eq. (2), where $h$, explicit given by Eq. (3), is the sensible energy, representing the energy obtained by temperature variation, and $\Delta H$, shown in Eq. (4), the latent energy released through the phase transformation. In these equations, $L$ represents the latent heat, $\beta$ liquid fraction, $c_{p}$ the specific heat at constant pressure, and $h_{\text {ref }}$ the enthalpy of the 
material at a reference temperature $T_{\text {ref }}$ (generally set as $298.15 \mathrm{~K})$.

In most studies, the nonlinear governing function of the heat extraction coefficient of meta $1 /$ mold interface is expressed by the exponential function in the form of $\mathrm{Eq}$. (5), in which the parameters A and B are constants parameters (usually obtained from experimental data).

Pure metals, which do not contain substantially alloying elements, exhibit only one phase transformation temperature, the melting temperature. When these materials, during a cooling process, reaches in a temperature equal to their melting temperature, the solidification phenomenon takes place, presenting a flat grain growth interface between the solid and liquid region.

$$
\begin{aligned}
& \beta=0 \quad \text { if } T<T_{\text {solidus }} \\
& \beta=1 \quad \text { if } T>T_{\text {liquidus }} \\
& \beta=\frac{T-T_{\text {solidus }}}{T_{\text {liquidus }}-T_{\text {solidus }}} \quad \text { if } \quad T_{\text {solidus }}<T<T_{\text {liq }} \\
& \frac{\partial}{\partial t}(\rho \vec{v})+\nabla \cdot(\rho \vec{v} \times \vec{v})=-\nabla p+\nabla \cdot \tau+\rho \vec{g} \\
& \boldsymbol{\tau}=\mu\left[\left(\nabla \vec{v}+\nabla \vec{v}^{T}\right)-\frac{2}{3} \nabla \cdot \vec{v} \mathbf{I}\right] \\
& T_{\text {solidus }}=T_{\text {melting }}+\sum_{i=0}^{N_{s}-1} m_{i} \frac{Y_{i}}{K_{i}} \\
& T_{\text {liquidus }}=T_{\text {melting }}+\sum_{i=0}^{N_{s}-1} m_{i} Y_{i} \\
& m_{i}=\frac{T_{\text {eutectic }}-T_{\text {melting }}}{Y_{i, \text { eutectic }}} \\
& \beta^{n+1}=\beta^{n}-\lambda \frac{\alpha_{p}\left(T-T^{*}\right) \Delta t}{\rho V L-\alpha_{p} \Delta t L \frac{\partial T^{*}}{\partial \beta}} \\
& T^{*}=T_{m e l t}+\sum_{i=0}^{N_{s}-1} m_{i} Y_{i} \beta^{K_{i}-1} \\
& \frac{\partial}{\partial t}\left(\rho Y_{i, l i q}\right)+\nabla \cdot\left(\rho \beta \vec{v}_{l i q} Y_{i, l i q}\right) \\
& =\nabla \cdot\left(\rho \beta D_{i, m, l i q} \nabla Y_{i, l i q}\right) \\
& -K_{i} Y_{i, l i q} \frac{\partial}{\partial t}(\rho(1-\beta)) \\
& +\frac{\partial}{\partial t}\left(\rho(1-\beta) Y_{i, l i q}\right)
\end{aligned}
$$

$$
\begin{gathered}
Y_{i, \text { sol }}=K_{i} Y_{i, l i q} \\
\vec{v}_{\text {liq }}=\frac{\vec{v}}{\beta} \\
q=h_{\text {global }}\left(T_{c}-T_{\text {water }}\right)
\end{gathered}
$$

When a metal alloy is analyzed, the phase transformation temperature is divided into liquidus temperature, at which nucleation begins, and solidus temperature, at which the solid state is established. The Aluminum-Silicon equilibrium diagram and its eutectic point can be seen in Fig. 1. The eutectic point is an invariant reaction point, where the entire liquid mixture solidifies without mushy zone, as a pure metal. It is usually the lowest temperature point for phase transformation. In the temperature range between the abovementioned temperatures an interfacial region, often called the mushy zone, is established momentarily, which has liquid fraction $\beta$ between 0 and 1 . Eq. (6) mathematically establishes this relation. The enthalpy-porosity technique treats the partially solidified region (mushy zone) as a porous medium. The porosity in each cell in this technique is established as the liquid fraction of that cell. In fully solidified regions the porosity is zero, there is no movement; in fully fluid, the porosity has a value of 1 . Proper terms are added in model equations to treat this phase transition as a continuum model.

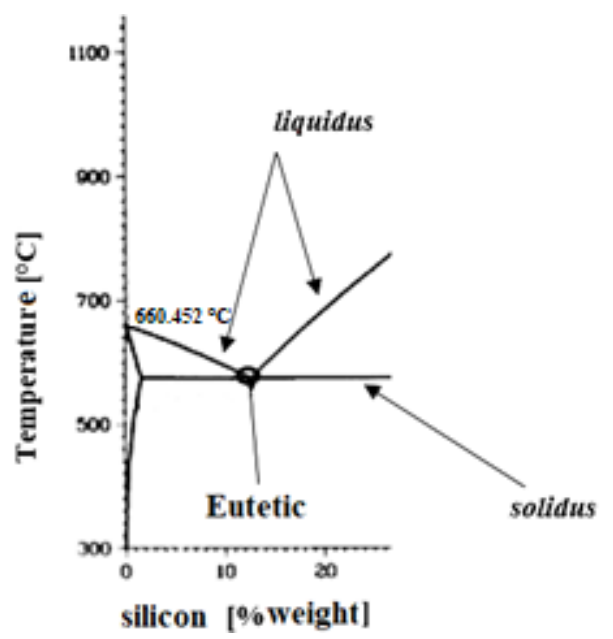

Figure 1. Main lines and points of the AluminumSilicon diagram. Adapted from ASM International (1990).

The momentum conservation equation can be seen in Eq. (7), where $p$ is the static pressure, $\tau$ a shear tensor (given by Eq. (8)), $\rho \vec{g}$ is the gravitational body force, $\mu$ the liquid dynamic viscosity and $\boldsymbol{I}$ the unitary tensor. It is important to consider that, since the velocity of the convective particles in the solidification phenomenon is very 
low, the flow is usually considered a laminar flow.

When a multicomponent liquid solidifies, the solute diffuses from the solid phase to the liquid phase. This effect is quantified by the partition coefficient of solute $i$, denoted $K_{i}$, which is the ratio of the mass fraction of the solid to that of the liquid at the interface. ANS YS FLUENT computes the solidus and liquidus temperatures of the species mixture using $m_{i}$ parameter, shown in Eq. (11), in Eqs. (9) and (10). $Y_{i}$ is the mass fraction of the solute $i, m$ is the slope of the liquidus surface with respect to $Y_{i}$ and $N_{s}$ is the number of species present in the mixture. If the value of the mass fraction $Y_{i}$ exceeds the value of the eutectic mass fraction, $Y_{i, \text { eutectic }}$, then $Y_{i}$ becomes into $Y_{i, \text { eutectic }}$.

The liquid fraction by Eq. (6) can cause numerical errors and convergence difficulties in multicomponent alloys, because its value is not known a priori. Therefore, it is necessary an iterative procedure to obtain this variable. The liquid fraction is obtained as shown in Eq. (12), where the index $n$ indicates the iteration number, $\lambda$ the relaxation factor, with a default value of $0.9, \alpha_{p}$ the cell matrix coefficient, $\Delta t$ the time step, $\rho$ the specific mass of the finite volume, $V$ the cell volume, $T$ is the temperature at cell and $T^{*}$ the temperature of the cell interface. The latter magnitude can be calculated when evaluated by Scheil's rule, which considers no backward diffusion by Eq. (13).

When the Scheil's model is used on the model, ANSYS FLUENT solves $Y_{i, l i q}$ as a dependent variable, using the partial differential equation shown in Eq. (14), and expression shown Eq. (15) and (16), where $\vec{v}_{l}$ is the velocity of the liquid and $D_{i, m, l}$ the mass diffusion coefficient of species $i$ in the liquid mixture. In Eq. (14), by definition, all property with index $i$ equal to 0 is null (once that null means solute free alloy).

The expression of the Eq. (5) will be implemented in the software through a user defined function (UDF). The formulation of Eq. (17) is used, where $T_{c}$ is the temperature of the finite volume in contact with the heat exchange interface and $T_{\text {water }}$ is the temperature of the water flow.

$$
\begin{gathered}
\frac{\partial \rho}{\partial t}+\nabla \cdot(\rho \vec{v})=0 \\
c_{p_{m z}}=\beta c_{p_{l}}+(1-\beta) c_{p_{s}} \\
K_{m z}=\beta \rho_{l} K_{s}+(1-\beta) \rho_{s} K_{s}
\end{gathered}
$$

It is important to state that, for casting processes where the heat extraction does not provide a quasiequilibrium phase transformation, it is necessary to use a different method than the lever rule, which provides more reasonable physical representation. The lever rule, which mathematically represents the behavior of the chemical species when in the process of solidification, considers that all the secreted solute is redistributed in the solid, imposing that the solidification apparatus allows a very high solidification time for adequate solute diffusion to take place. The imposition of back diffusion to the solid in conventional casting is impossible since the ingot is solidified in a few minutes in most cases. Considering the uniformity of solute mixing in the solvent and no backward diffusion, the Scheil model was used to represent the behavior of solute segregation during solidification. The equation of conservation of mass (or continuity equation) can be expressed according to Eq. (18), which is valid for incompressible fluids. In this case, there is no source term.

Some thermophysical properties will be considered constant (which are shown in Tab. 1), since more rigorous analysis of these phenomena is not relevant considering the present study. To adequately explain the variation of some thermophysical properties involved in the solidification process, due their great impact on the heat transfer process, the specific heat and thermal conductivity functions, of the constituent elements of the alloy, by temperature range, are shown in Tab. 2, the properties present in this table were adapted from Gandin (2000) and Ioffe (2018) (Retrieved May 15, 2018, from: http://www.ioffe.ru/SVA/NSM/Semicond/Si/).

Table 1. Thermophysical properties of the chemical ele ments and alloys under study. Adapted from Peres (2005).

\begin{tabular}{|c|c|c|c|}
\hline Properties & $\mathrm{Al}$ & $\mathrm{Si}$ & Binary \\
\hline Melting Latent Heat, $L\left[{ }^{\circ} \mathrm{C}\right]$ & 385000 & - & 389187 \\
\hline Melting Temperature, $T_{L}\left[{ }^{\circ} \mathrm{C}\right]$ & 660 & 1414 & - \\
\hline Liquidus Temperature, $T_{F}\left[{ }^{\circ} \mathrm{C}\right]$ & - & - & 644 \\
\hline Eutectic Temperature, $T_{E}\left[{ }^{\circ} \mathrm{C}\right]$ & - & - & 577 \\
\hline Partition Coefficient, $k$ & - & 0.1307 & - \\
\hline Solid Specific Heat, $c_{p_{s}}[\mathrm{~J} / \mathrm{kg} . \mathrm{K}]$ & 1123 & - & 963 \\
\hline $\begin{array}{c}\text { Liquid Specific Heat, } c_{p_{l}} \\
{[\mathrm{~J} / \mathrm{kg} . \mathrm{K}]}\end{array}$ & 1086 & - & 1084 \\
\hline Thermal Cond. solid, $K_{s}[\mathrm{~W} / \mathrm{m} . \mathrm{K}]$ & 222 & 141 & 121 \\
\hline $\begin{array}{c}\text { Thermal Cond. liquid, } K_{l} \\
{[\mathrm{~W} / \mathrm{m} . \mathrm{K}]}\end{array}$ & 92 & 430 & 91 \\
\hline Solid Density, $\rho_{s}\left[\mathrm{~kg} / \mathrm{m}^{3}\right]$ & 2550 & 2330 & 2695 \\
\hline Liquid Density, $\rho_{l}\left[\mathrm{~kg} / \mathrm{m}^{3}\right]$ & 2380 & 2530 & 2385 \\
\hline \multicolumn{2}{|c|}{} & & \\
\hline
\end{tabular}

In the mushy zone, the specific heat is interpolated according to the local liquid fraction, from a mixing law, as shown in Eq. (19), while the thermal conductivity is interpolated by a mixing law mass weighted, as in Eq. (20).

\section{NUMERICAL METHOD}

The alloy Al-3wt\%Si was chosen due to the 
importance that this system has in the mechanical industry. The schematic of casting assembly used in solidification experiments is presented in the Fig. (2).

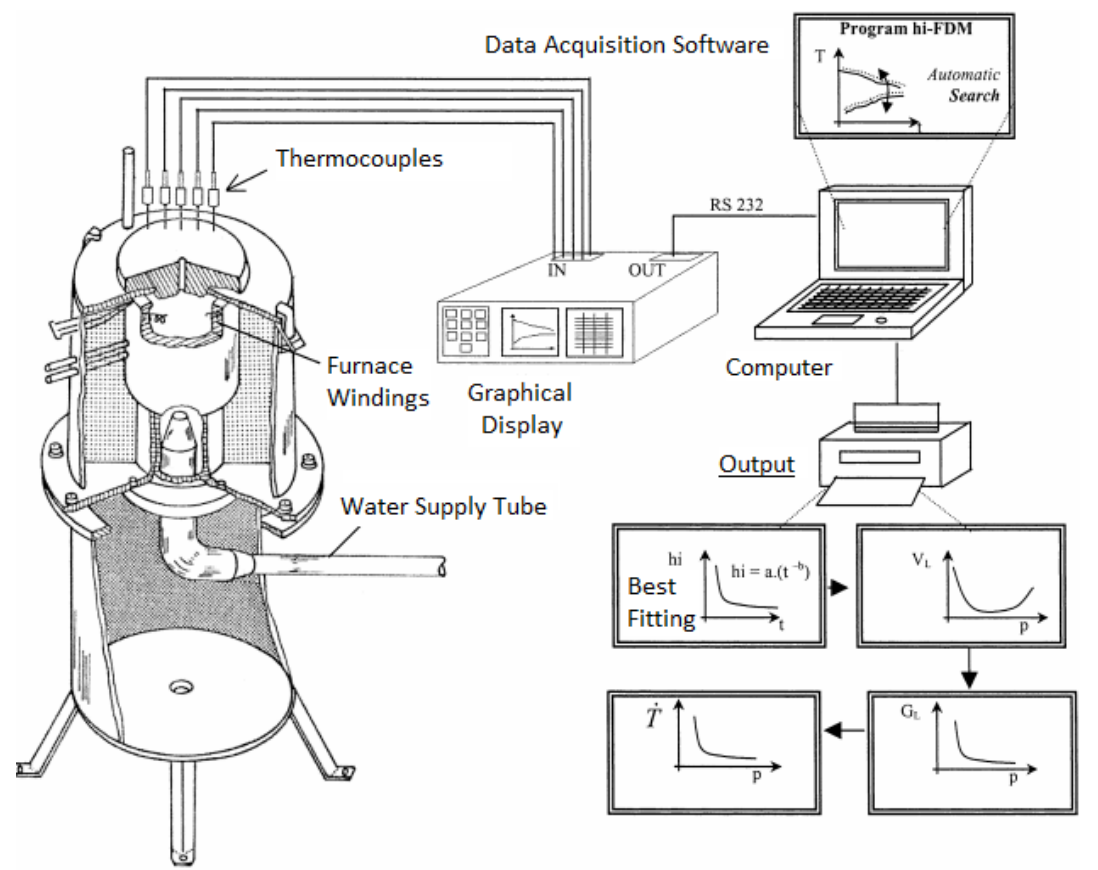

Figure 2. Schematic of the experimental apparatus (Siqueira et al., 2002).

In the experimental data, a stainless-steel mold was used, which had an internal diameter of $50 \mathrm{~mm}$, $110 \mathrm{~mm}$ height, and $5 \mathrm{~mm}$ wall thickness. The inner vertical surface was covered with a layer of insulating alumina to minimize radial heat losses, and a top cover made of an insulating material was used to reduce heat losses from metal/air surface. The bottom part of the mold was closed with a thin $(3 \mathrm{~mm})$ disc of carbon steel. The alloy was melted in situ and the lateral electric heaters had their power controlled to permit a desired superheat to be achieved to simulate the correct pouring temperature for the binary. To begin solidification, the electric heaters were disconnected, and the same time, the water flow was initiated. Temperatures in the casting were monitored during solidification by a array of type $\mathrm{K}$ thermocouples (1.6- $\mathrm{mm}$ ) accurately positioned with respect to the heat extracting surface (Siqueira et al., 2002). The thermocouples were inserted in the ingot in the positions 4,8 and 12 from the bottom interface.

The thermophysical properties of Al-Si alloy and the mold plate material utilized in the simulation are presented in Tab. 1. The software ANSYS FLUENT was used to perform the simulation of the vertical upward solidification with water-cooling. The mesh has 17920 elements distributed as shown in the Fig. 3. These dimensions are the same used by experimental setup exposed in Peres et al. (2004).

As boundary conditions, the cylinder was thermally insulated in all the walls, except the bottom where it is in direct contact with a cylindrical metal plate of $4 \mathrm{~mm}$ width (not shown in figure), which was cooled by water at $300 \mathrm{~K}$. The initial temperature of simulation was $919.15 \mathrm{~K}$. During this simulation the laminar fluid, energy and solidification models were active. The results were obtained after a total time of 200 seconds, with 0.1 seconds time step. Details regarding the mathematical models and numerical methods used on the simulation are available in ANSYS (2013).

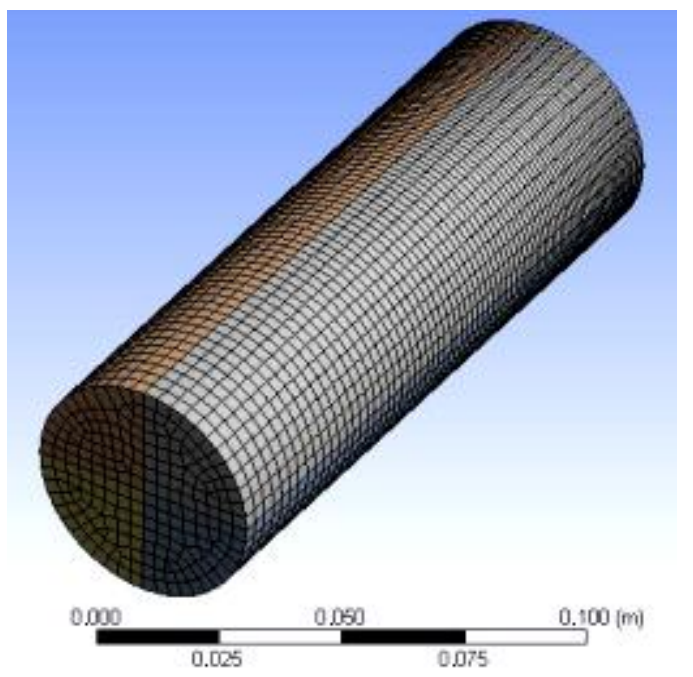

Figure 3. Mesh and geometry used in the simulation.

At last, in Tab. 3 is expressed the liquidus temperature considered in the numerical analysis. Considering that ANSYS calculates the liquidus temperature using the slope of the liquidus curve, the numerical value of the temperature in question is 
slightly different from the experimental one. However, the low relative error of the liquidus temperature in ANSYS relative to the experimental one provides a good physical representation of the phenomenon.

Table 3. Experimental and analytical liquidus temperature, considering specific slope.

\begin{tabular}{|c|c|c|c|c|c|}
\hline Binary & Slope & $\begin{array}{c}\text { Pouring } \\
\text { Temperature }\end{array}$ & $\begin{array}{c}\text { Liquidus } \\
\text { Temperature } \\
\text { (Experimental) }\end{array}$ & $\begin{array}{c}\text { Liquidus } \\
\text { Te mperatur } \\
\text { e(ANSYS) }\end{array}$ & $\begin{array}{c}\text { Relative } \\
\text { Error }\end{array}$ \\
\hline $\mathrm{Al}-3 \% \mathrm{Si}$ & -569.04 & $919.15 \mathrm{~K}$ & $917.15 \mathrm{~K}$ & $916.45 \mathrm{~K}$ & $0.076 \%$ \\
\hline
\end{tabular}

\section{RESULTS AND DISCUSS ION}

The Figure 4 shows the results of the temperature field in the simulated ingot. It is worth pointing out that the liquid-solid interface in quite sharp, presenting irrelevant instabilities, resulting in a steady place of growth, providing a sharp transformation of grains (Columnar-to-Equiaxed Transition), as shown in Gandin (2000) for this alloy and other from alu minu m-silicon system.

In Figure 5 is shown the liquid fraction of the ingot after 5 seconds of solidification. When compared with Fig. 4, Fig. 5 confirms the same behavior of the liquid-solid interface: sharp with no considerable movement due gravity.

No convergence difficulties are observed, and numerical results and experimental profiles exhibit good agreement in the thermocouple positions analyzed. In this context, the absence of very detailed experimental data (mainly in the initial seconds), does not allow adjustment of numerical setup. The main concern here is the absence of mathe matical and reliable model of metal-mold contact resistance and more information about rate of water heat extraction at bottom surface.
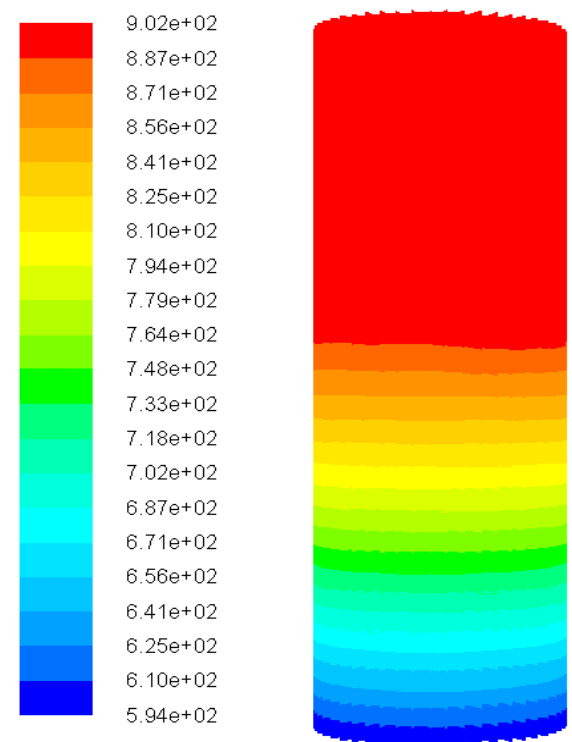

Contours of Static Temperature (k) $($ Time $=9.0000 e+01)$

Figure 4. Ingot temperature distribution at 9 seconds.

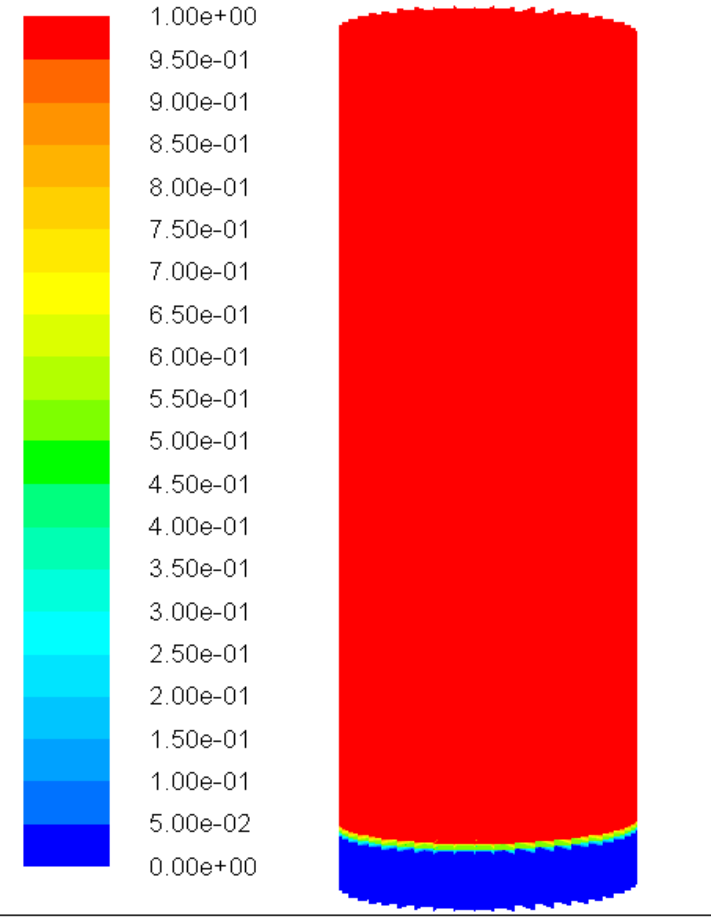

\section{Contours of Liquid Fraction (Time $=5.0000 \mathrm{e}+00$ )}

Figure 5. Ingot liquid fraction at 5 seconds.

In Figure 6 is shown the experimental and numerical thermal profiles of the solidification of Al$3 \%$ Si alloy, along the thermocouples positions.

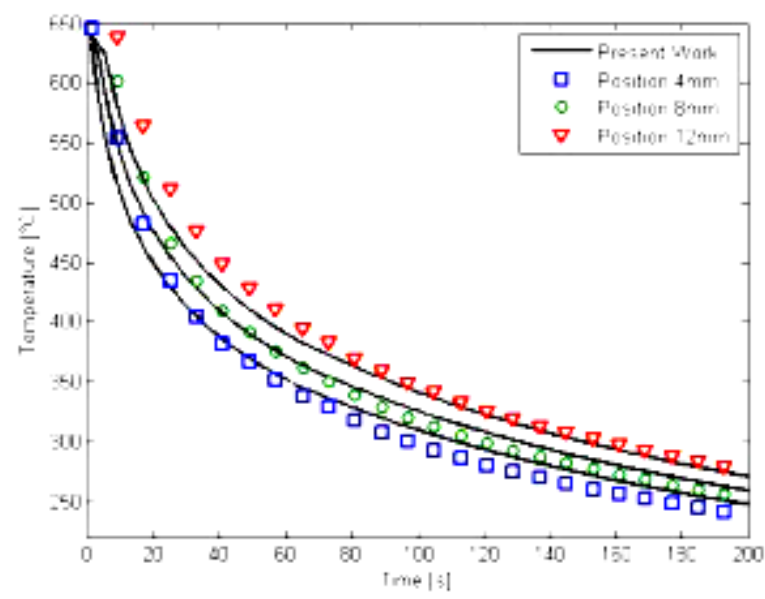

Figure 6. Comparison between experimental and simu lated thermal profiles.

The Finite Volume Method used in this paper, even when applying a coarse mesh on the analysis, can be comparable with the results presented by Finite Difference Method. However, there is no assertion about the thermal profile difference if the mesh were more refined. Thus, changing the mesh can significantly modify the results presented, since the features as phase transformation and thermosolutal convection are highly dependent on spatial and te mporal resolution. 


\section{CONCLUSIONS}

In this work, it was presented a numerical methodology to simulate solid ification of alloys using Ansys software. The simulation done enables visualization of the progress of solidification inside a casting. The comparison of the simulated thermal profiles and the experimental ones shows that the numerical simulation of forced cooling of Al 3wt.\% Si alloy is efficient and can be used to obtain thermal evolution along the casting. The fast setup and analysis of new models to heat transfer in metal mold interface can also be done. The numerical simu lation allows a great number of solidification models to be applied and compared. Future studies can be done to verify if the number of nodes is enough to simulate this type of phenomenon. Different options regarding fluid convection, diffusion and heat transfer are available and will be applied in future works.

\section{REFERENCES}

ANSYS, 2013, Theory Guide, Release 14.5, Help System, ANSYS, Inc.

ASM International, 1990, Binary Alloy Phase Diagrams, 2nd Edition.

Castanho, M. A. P., Goulart, P. R., Brito, C., Spinelli, J. E., Cheung, N., and Garcia, A., 2015, Steady and Unsteady State Peritectic Solidification, Materials Science and Technology, Vol. 31, No. 1, pp. 105-114.

Gandin, C. A., 2000, From Constrained to Unconstrained Growth During Directional Solidification, Acta Materialia, Vol. 48, No. 10, pp. 2483-2501.

Hachani, L., Saadi, B., Wang, X. D., Nouri, A., Zaidat, K., Belgacem-Bouzida, A., and Fautrelle, Y., 2012, Experimental Analysis of the Solidification of Sn-3wt.\% Pb Alloy Under Natural Convection, International Journal of Heat and Mass Transfer, Vol. 55, No. 7-8, pp. 1986-1996.

Hernandez, M. J. Q., Pero-Sanz, J. A., and Verdeja, L. F., 2017, Solidification and Solid-State Transformations of Metals and Alloys, Elsevier.

Peres, M. D., Siqueira, C. A., and Garcia, A., 2004, Macrostructural and Microstructural Development in Al-Si Alloys Directionally Solidified Under Unsteady-State Conditions, Journal of Alloy and Compounds, Vol. 381, No. 1-2, pp. 168181.

Şahin, H. M., Kocatepe, K., Kayıkc1, R., and, Akar, N., 2006, Determination of Unidirectional Heat Transfer Coefficient During Unsteady-State Solidification at Metal Casting-Chill Interface, Energy Conversion and Management, Vol. 47, No. 1, pp. 19-34.

Siqueira, C. A., Cheung, N., and Garcia, A., 2002, Solidification Thermal Parameters Affecting the Columnar-to-Equiaxed Transition, Metallurgical and Materials Transaction, Vol. 33, No. 33, pp. 2107-2118.
Vida, T. A., Freitas, E. S., Brito, C., Cheung, N., Arenas, M. A., Conde, A., and Garcia, A., 2016, Thermal Parameters and Microstructural Development in Directionally Solidified Zn-Rich ZnMg Alloys, Metallurgical and Materials Transactions A, Vol. 47, No. 6, pp. 3052-3064.

Voller, V. R., and Prakash, C., 1987, A Fixed Grid Numerical Modelling Methodology for Convection-Diffusion Mushy Region Phase-Change Problems, International Journal of Heat and Mass Transfer, Vol. 30, No. 8, pp. 1709-1719.

Wu, M., Ludwig, A., and Kharicha, A., 2017, A Four Phase Model for the Macrosegregation and Shrinkage Cavity During Solidification of Steel Ingot, Applied Mathematical Modelling, Vol. 41, pp. 102-120.

Wu, M., Zheng, Y., Kharicha, A., and, Ludwig, A., 2016, Numerical Analysis of Macrosegregation in Vertically Solidified $\mathrm{Pb}-\mathrm{Sn}$ Test Castings-Part I: Columnar Solidification, Computational Materials Science, Vol. 124, pp. 444-455. 